\title{
Purification and characterization of membrane-bound peroxidases from Metroxylon sagu.
}

\begin{abstract}
Two membrane-bound peroxidases, mPOD-I and mPOD-II, have been isolated and purified from Metroxylon sagu, using a combination of temperature-induced phase partitioning, DEAE-Toyopearl 650M, CM-Toyopearl $650 \mathrm{M}$ and gel filtration. The mPOD-I and mPOD-II had molecular mass of 51.2 and $43.8 \mathrm{kDa}$, respectively, as determined by SDS-PAGE. Both enzymes showed high efficiency of interaction with the substrates. The isoenzymes were highly inhibited by ascorbic acid, metabisulfite, l-cysteine and p-coumaric acid. The inhibition mode of action and inhibition rate constant $(\mathrm{Ki})$ values for these inhibitors were determined. Their activities were highly enhanced by $\mathrm{Al} 3+, \mathrm{Ca} 2+$ and $\mathrm{Fe} 3+$ but they were moderately inhibited by $\mathrm{Zn} 2+$.
\end{abstract}

Keyword: Metroxylon sagu; Pith; Membrane-bound peroxidases; Purification; Characterization. 